\title{
Aqueous humor penetration of topical bimatoprost $0.01 \%$ and bimatoprost $0.03 \%$ in rabbits: response to authors
}

This article was published in the following Dove Press journal:

Clinical Ophthalmology

9 August 20II

Number of times this article has been viewed

\author{
Joan-En Chang-Lin \\ Amy L Batoosingh \\ David A Hollander \\ Rhett M Schiffman \\ Diane D-S Tang-Liu \\ Allergan, Inc, Irvine, CA, USA
}

Correspondence: Joan-En Chang-Lin

Clinical Pharmacology

Allergan, Inc, 2525 Dupont Drive, TI-IL,

Irvine, CA 926I2, USA

Tel +l 7l 42464680

Fax + I 7147963138

Email lin_joan-en@allergan.com
We read with great interest the recent article by Ogundele and Jasek, ${ }^{1}$ in which the authors concluded that bimatoprost ophthalmic solution $0.01 \%$ (Lumigan $^{\circledR}$; Allergan, Inc, Irvine, CA) produced lower bimatoprost acid concentration than bimatoprost ophthalmic solution $0.03 \%$ (Lumigan; Allergan, Inc) in the aqueous humor of rabbits. This conclusion was made based on two treatment time points (30 and 90 minutes) with a small sample size $(n=4)$ at each time point and with large variability.

In comparing pharmacokinetic profiles of two formulations, it is a general practice that the study design would support assessment of the speed of onset (ie, time to maximum exposure $\left[\mathrm{T}_{\text {max }}\right]$ ), and the extent of absorption (ie, maximum concentration and area under the concentration-time curve). Therefore, a more complete temporal profile would be necessary. An erroneous conclusion could be drawn based on two seemingly arbitrary time points. For example, it is unclear whether these two time points reside in the ascending or descending portion of the temporal profile or if they reside one in each portion and the $\mathrm{T}_{\max }$ is missing.

Based on two data points, Ogundele and Jasek ${ }^{1}$ hypothesized that bimatoprost $0.01 \%$ might have compromised the intraocular pressure (IOP)-lowering effect. Not only is there no reported correlation of animal pharmacokinetic and/or metabolism results to clinical efficacy, this hypothesis directly contradicts existing evidence. A multicenter, 12-month, randomized, controlled trial demonstrated equivalent efficacy of bimatoprost $0.01 \%$ and bimatoprost $0.03 \%$ based on predetermined IOP criteria (limits of the $95 \%$ confidence interval of the between-group difference in mean IOP within $\pm 1.5 \mathrm{mmHg}$ at all time points and within $\pm 1 \mathrm{mmHg}$ at most time points). ${ }^{2}$

In addition, Ogundele and Jasek ${ }^{1}$ speculated that bimatoprost $0.01 \%$ might have increased the risk of ocular toxicity, based on prior publications of in vitro and animal studies that may not be relevant to patients, case series, or open-label clinical studies. This evidence is considered lower level compared with randomized, controlled trials. Katz et $\mathrm{al}^{2}$ conducted a randomized, controlled trial and reported bimatoprost $0.01 \%$ had (a) significantly lower overall incidence of treatment-related adverse events $(P<0.03)$; (b) significantly reduced conjunctival hyperemia $(P<0.044)$, skin pigmentation $(P<0.02)$, and eye pruritus $(P<0.035)$; and (c) significantly lower discontinuation rates than bimatoprost $0.03 \%(P=0.043)$. Based on clinical trial evidence, the claims of ocular toxicity are unfounded for at least 12 months of administration as monotherapy. ${ }^{2}$ In addition, a recent clinical study comparing ocular surface tolerability of topical prostaglandin analogs demonstrated no statistical differences following 3 months of 
treatment in either corneal staining or conjunctival hyperemia between latanoprost, which has 200 ppm benzalkonium chloride (BAK), similar to bimatoprost $0.01 \%$, and travoprost ophthalmic solution $0.004 \%$ (Travatan $Z^{\circledR}$; Alcon Laboratories, Inc, Fort Worth, TX) (BAK free, preserved with sofZia ${ }^{\circledR}$ [Alcon Laboratories, Inc]). ${ }^{3}$

Bimatoprost $0.01 \%$, which offers improved ocular tolerability while maintaining the established efficacy of bimatoprost $0.03 \%$, recently gained approval by the European Medicines Evaluation Agency (2009) and the US Food and Drug Administration (2010) as first-line therapy in patients with open-angle glaucoma or ocular hypertension. Any ophthalmologist or patient concerns raised by the incomplete and potentially misleading conclusion published by Ogundele and Jasek $^{1}$ can be addressed with a carefully constructed pharmacokinetic study with a complete time-concentration profile. We are currently preparing a manuscript that reports the findings of such a study design.

\section{Disclosure}

The authors are employees of Allergan, Inc.

\section{References}

1. Ogundele AB, Jasek MC. Aqueous humor penetration of topical bimatoprost $0.01 \%$ and bimatoprost $0.03 \%$ in rabbits. Clin Ophthalmol. 2010;4:1447-1450

2. Katz LJ, Cohen JS, Batoosingh AL, et al. Twelve-month, randomized, controlled trial of bimatoprost $0.01 \%, 0.0125 \%$, and $0.03 \%$ in patients with glaucoma or ocular hypertension. Am J Ophthalmol. 2010;149(4):661-671.

3. Whitson JT, Trattler WB, Matossian C, et al. Ocular surface tolerability of prostaglandin analogs in patients with glaucoma or ocular hypertension. J Ocul Pharmacol Ther. 2010;26(3):287-292.
Clinical Ophthalmology

\section{Publish your work in this journal}

Clinical Ophthalmology is an international, peer-reviewed journal covering all subspecialties within ophthalmology. Key topics include: Optometry; Visual science; Pharmacology and drug therapy in eye diseases; Basic Sciences; Primary and Secondary eye care; Patient Safety and Quality of Care Improvements. This journal is indexed on

Submit your manuscript here: http://www.dovepress.com/clinical-ophthalmology-journal

\section{Dovepress}

PubMed Central and CAS, and is the official journal of The Society of Clinical Ophthalmology (SCO). The manuscript management system is completely online and includes a very quick and fair peer-review system, which is all easy to use. Visit http://www.dovepress.com/ testimonials.php to read real quotes from published authors. 